\title{
AFIBRINOGENEMIA SECUNDÁRIA A ACIDENTE OFÍDICO CROTÁLICO \\ (Crotalus durissus terrificus)
}

\author{
C. F, S. AMARAL (1), N. A. REZENDE (2), T. M. G. PEDROSA (3), O. A. da SILVA (2) \& E. R. P. PEDROSO (1)
}

\section{R E S U M O}

Relatam se os casos de dois pacientes que desenvolveram afibrinogenemia sem consumo de plaquetas após terem sido picados por Crotalus durissus terrificus. Ambos também tiveram insuficiencia renal aguda de alto débito e no caso n: 2 foi feito o diagnóstico de rabdomiólise através da elevação expressiva dos niveis séricos de CPK e DHL. O caso n: 1 recebeu dose nảo especificada de antiveneno e foi tratado com ácido épsilon aminocaproico e transfusảo de sangue fresco total tendo apresentado normalização dos testes de coagulação 40 horas após estas medi das. O caso n: 2 recebeu dose adequada de antiveneno crotálico e 12 horas depois já evidenciava recuperaçáo do distúrbio da coagulaçāo. $O$ caso n" 1 evoluiu sem apresentar hemorragias. O caso n: 2 apresentou sangramento persistente nos locais de venóclise e após remoção de crostas de impetigo nas pernas. Ambos receberam tratamento conservador para a insuficiencia renal aguda e tiveram alta com recupe. raçāo da funçāo renal.

UNITERMOS: Afibrinogenemia: Acidente ofídico crotálico

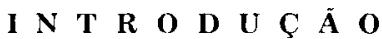

$O$ veneno da cascavel sul-americana apresenta atividades neurotóxica ${ }^{8}$, miotóxica ${ }^{2}{ }^{14}$, coa gulante ${ }^{8.9 .10 .15 .17}$, e hemolítica "in vitro" "6. 7.16 discu tindo-se a existência desta açào "in vivo"3.4.

Embora observados "in vitro", os distúrbios de coagulação produzidos pelo veneno da Crotalus durissus terrificus sāo pouco decritos nos acidentados por esta serpente ${ }^{1}$, sendo destacada a elevada freqüencia com que apresentam pro longamento do tempo de coagulação ${ }^{13}$.
O objetivo deste trabalho é relatar dois casos de pacientes picados pela cascavel sul-america na que apresentaram incoagulabilidade sangüí nea secundária à afibrinogenemia sem consumo de plaquetas.

\section{RELATO DOS CASOS}

Caso n: 1 - WLG, 11 anos, masculino, leucodermo, foi picado no tornozelo esquerdo por uma cascavel às $11: 30 \mathrm{~h}$ do dia 2 de julho de 1977 . Trinta minutos após a picada o paciente recebeu

\footnotetext{
Trabalho realizado no Centro de Tratamento Intensivo do Hospital das Clinicas da Universidade Federal de Minas Gerais. Belo Horizonte, MG, Brasil.

(1) Professor Adjunto do Departamento de Clinica Medica da Faculdade de Medicina da UFMG. Médico do CTI do Hospital das Clinicas da UFMG. Av. Prof Alfredo Balena, 110. CEP 30130. Belo Horizonte, MG, Brasil.

(2) Professor Assistente do Departamento de Clínica Médica da Faculdade de Medicina da UFMG. Médico do CTI do Hospital das Clinicas da UFMG. Belo Horizonte. MG, Brasil.

(3) Medica do CTI do Hospital das Clinicas da UFMG, Belo Horizonte. MG, Brasil
} 
AMARAL, C. F. S.: REZENDE, N. A.; PEDROSA, T. M. G.: SILVA, O. A. da \& PEDROSO, L. P D. - Afibrinogenemia secundaria a acidente ofidico crotálico (Crotalus durissus terrificus). Rev. Inst. Med. trop. Sảo Paulo, 30 (4): $288-292,1988$.

em hospital soro anti-ofídico em quantidade e qualidade não especificadas. Nas horas subs qüentes desenvolveu edema no local da picada, dor muscular generalizada, confusão mental e vômitos. No dia seguinte apresentou ptose pal. pebral bilateral, oftalmoplegia, urina averme lhada e oliguria, sendo transferido para o CTI do Hospital das Clinicas da UFMG com o diag nóstico de insuficiencia renal aguda secundária a acidente por Crotalus durissus terrificus. $\mathrm{O}$ exame físico no CTI mostrou paciente consciente com fácies neurotóxica. Havia edema discreto no tornozelo (local da picada). As extremidades estavam quentes, bem perfundidas, acianóticas. O pulso era $80 \mathrm{bpm}$, a pressão arterial 130 100 $\mathrm{mmHg}$, a freqüència respiratória $40 \mathrm{irpm}$ e a tem peratura axilar $35,6^{\circ} \mathrm{C}$. Não foram detectadas al teraçōes no exame dos aparelhos respiratório, cardiovascular e digestivo. Os exames laboratoriais revelaram: uréia $80 \mathrm{mg} \%$, creatinina 3,3 $\mathrm{mg} \%$, glicemia $140 \mathrm{mg} \%$, cloretos $97 \mathrm{mEq} / \mathrm{L}$, po tássio $6,0 \mathrm{mEq} / \mathrm{L}$, sódio $136 \mathrm{mEq} / \mathrm{L}$, bilirrubina direta $0,24 \mathrm{mg} \%$, bilirrubina total $0,98 \mathrm{mg} \%$, al bumina $3,8 \mathrm{~g} \%$, hemoglobina $17,3 \mathrm{~g} \%$, hemácias $5,08 \times 10^{6} / \mathrm{mm}^{3}$, hematócrito $50 \%$, reticulócitos $60.960 / \mathrm{mm}^{3}$, leucócitos $15.700 / \mathrm{mm}^{3}$ com desvio para a esquerda. O exame de rotina da urina mostrou pigmento heme ++++ , proteinúria ++ , glicosúria ++ e poucos cilindros granulo sos. Os testes de coagulação (realizados 32 horas após a pícada) revelaram plaquetas $300.000 / \mathrm{mm}^{3}$, TC infinito, tempo de protrombina infinito, fibrinogênio indosável e tempo de trom boplastina parcial superior a 180 segundos (controle 30-60s). Apesar destas alteraçoes nāo se observaram manifestaçōes hemorrágicas. Baseado nos resultados dos testes de coagulação foi feito

\section{QUADRO 1}

Resultados dos testes de coagulaça realizados no paciente do caso n: 1 apos picada por Crotalus durissus terrificus

\begin{tabular}{lccc}
\hline \multirow{2}{*}{ Teste } & valor normal & \multicolumn{2}{c}{ horas após a picada } \\
& & 32 & 75 \\
\hline TC (min) & 15 & infinito & - \\
TP (s) & 13 & infinito & 11,5 \\
TTP (s) & 40.60 & 180 & 50 \\
Fibrinogênio $\left(\mathrm{mg}^{2}\right)$ & $150-350$ & zero & 390 \\
Plaquetas $\left(\mathrm{X} 10^{3} / \mathrm{mm}^{3}\right)$ & 150350 & 300 & 298 \\
\hline
\end{tabular}

$\mathrm{TC}=$ tempo de coagulaçāo: $\mathrm{TP}=$ tempo de protrombina: $\mathrm{TT} \mathrm{P}$ = tempo de tromboplastina parcial o diagnóstico de afibrinogenemia. O paciente foi medicado com $3,0 \mathrm{~g}$ de ácido épsilon aminoca próico endovenoso seguidos de $1,5 \mathrm{~g}$ endovenoso de $4 / 4 \mathrm{~h}$ durante $24 \mathrm{~h}$ e recebeu transfusāo de $500 \mathrm{ml}$ de sangue fresco total. A evolução dos testes de coagulação encontra se no Quadro 1

A insuficiência renal aguda foi tratada con servadoramente, assumindo padrāo de alto dé bito com volume urinário diário superior a 1300 $\mathrm{ml}$, tendo havido, nos 7 dias subseqüentes, eleva ção dos niveis séricos de uréia (até $270 \mathrm{mg} /$ ) e de creatinina. A partir de entāo houve recupe ração progressiva da função renal tendo o pa ciente recebido alta hospitalar assintomático 13 dias após a internaçāo.

Dois meses após o acidente ofídico o pacien te foi examinado no ambulatório e nảo eviden ciou alteraçoes clínico-laboratoriais.

Caso n: 2 - WS, 17 anos, masculino, faioderma, lavrador, residente em Bonfim ( $M G$ ), portador de dislalia congênita, foi picado por cascavel no dorso do pé direito quando retornava do traba lho na tarde do dia 16 de julho de 1987. Logo após a picada passou a apresentar fraqueza mus cular generalizada e urina avermelhada. As 17:30 $h$ do dia seguinte foi transferido para o Pronto Socorro de Belo Horizonte onde chegou confuso. com ptose palpebral bilateral, apresentando ao exame físico hipotonia e hiporeflexia generali zadas, extremidades frias e mal perfundidas, su dorese abundante, taquipnéia com batimentos de aletas nasais. A pressão arterial era 110/80 mmHg com o paciente deitado e era impercep tível com o mesmo assentado. As bulhas eram rítmicas e os pulmões não apresentavam ruidos adventícios à ausculta. Os exames laboratoriais mostraram hemácias $6.100 .000 / \mathrm{mm}^{3}$, hemoglobi na $18,2 \mathrm{~g} \%$, hematócrito $53 \%$, leucócitos $24.000 / \mathrm{mm}^{3}$ com contagem diferencial normal, glicemia $135 \mathrm{mg} \%$, uréia $98 \mathrm{mg} \%$, creatinina 2,0 $\mathrm{mg} \%$, sódio $132 \mathrm{mEq} / \mathrm{L}$, potássio $6,2 \mathrm{mEq} / \mathrm{L}$, clo retos $100 \mathrm{mEq} / \mathrm{L}$, tempo de coagulaçāo acima de $40 \mathrm{~min}$, tempo de protrombina superior a 50 s, fibrinogênio $74 \mathrm{mg} \%$. A té a admissão no hos pital Pron to Socorro o paciente não havia rece. bido nenhum tratamento. Foi entào administra do por via intravenosa antiveneno para neutra. lizar $300 \mathrm{mg}$ de veneno crotálico sendo o paciente transferido para o CTI do Hospital das Clínicas da UFMG com os diagnósticos de choque, dis- 
AMARAL, C. F. S.: REZENDE, N. A.: PEDROSA. T. M. G : SILVA. O. A da \& PEDROSO. E. R. P. - Afibrinogenernia secundária a acidente ofídico crotálico (Crotalus durissus terrificus). Rev. Inst. Med. trop. Sảo Paulo, 30 (4): 288292,1988

túrbio da coagulação e insuficiência renal aguda secundários a acidente crotálico. Ao ser admi tido no CTI o paciente estava confuso e com prurido cutâneo generalizado e ao exame fisico apresentava fácies neurotóxica, edema palpe bral bilateral, reação urticariforme generalizada. extremidades frias e mal perfundidas. A pressāo arterial era imperceptivel, a frequéncia cardiaca $140 \mathrm{bpm}$ e a respiratória $36 \mathrm{irpm}$. A ausculta res piratória era normal. Observaram se discreto edema no dorso e tornozelo do pé direito.sangra mento persistente nos locais de venóclise e durante a limpeza dos impetigos localizados nos membros inferiores bem como hematoma signi ficativo após punçāo da artéria radial. Os exames laboratoriais realizados após a admissāo no CTI revelaram hemoglobina $18,7 \mathrm{~g} \%$, hemácias $8.300 .000 / \mathrm{mm}^{3}$, hematócrito $54 \%$, leucócitos $17.800 / \mathrm{mm}^{3}$, glicemia $98 \mathrm{mg} \%$, uréia $77 \mathrm{mg} \%$, creatinina 1,8 $\mathrm{mg} \%$, sódio $144 \mathrm{mEq} / \mathrm{L}$, cálcio 9,1 $\mathrm{mg} \%$, potássio $5,8 \mathrm{mEq} / \mathrm{L}$, cloretos $102 \mathrm{mEq} / \mathrm{L}$, albumina $3,4 \mathrm{mg} \%$, transaminase glutâmico oxalacética $1330 \mathrm{mU} / \mathrm{L}$, creatinafosfoquinase $33.000 \mathrm{mU} / \mathrm{L}$, ácido úrico $13,0 \mathrm{mg} \%$, fósforo 5,9 $\mathrm{mg} \%$. $\mathrm{PH}$ arterial $7,335, \mathrm{PaCO}_{2}, 22,9 \mathrm{mmHg}$, $\mathrm{PaO}_{2}$ 49,0 mmHg, BE $9,1 \mathrm{mEq} / \mathrm{L}$ tempo de coagulação infinito, tempo de protrombina maior que 52s, tempo de tromboplastina parcial superior a 180 s (controle $35 \mathrm{~s}$ ), fibrinogênio indosável e plaquetas $242.000 / \mathrm{mm}^{3}$. Foi introduzida sonda vesical de demora obtendo-se pequena quantidade de urina de coloraçâo vinhosa. O exame de roti na desta urina mostrou proteinúria +++ , glico súria $++t$, pigmento heme $++t, 12$ hemácias por campo e alguns leucócitos agrupados.

O paciente recebeu de imediato adrenalina intravenosa, hidrocortisona e infusāo de crista lóides para tratamento da reaçào anafilactóide ao antiveneno crotálico e do choque. Com estas medidas houve melhora da perfusão capilar e normalização da pressăo arterial, persistindo a oligúria. Foram entāo administrados $100 \mathrm{mg}$ de furosemide intravenoso ocorrendo na hora subseqüente diurese de $700 \mathrm{ml}$. Nas 24 horas seguin tes houve persistencia da poliúria mas com elevaçāo dos níveis de ureia e creatinina séricas (130 $\mathrm{mg} \%$ e $2,8 \mathrm{mg} \%$ respectivamente), caracterizando insuficiência renal aguda de alto débito. A partir do segundo dia de internação no CTI notou-se redução das escórias nitrogenadas e no terceiro dia o pacien te recebeu alta do setor após recuperar a estabilidade dos sistemas fisiológicos. Neste dia os exames laboratoriais revelaram ureia $42 \mathrm{mg} \%$. creatinina $1.7 \mathrm{mg} \%$, sódio 138 $\mathrm{mEq} \mathrm{L}$, potássio $3.8 \mathrm{mEq} \mathrm{L}$. cloretos $100 \mathrm{mEq} / \mathrm{L}$ desidrogenase lática $3000 \mathrm{mU} \mathrm{L}$, creatina-fosfo quinase $3.920 \mathrm{mU} \mathrm{L}$, hemoglobina $15,4 \mathrm{~g} \%$, he matócrito $45 \%$, hemácias $4.870 .000 / \mathrm{mm}^{3}$ e leucó citos $9500 / \mathrm{mm}^{3}$. A evolução dos testes de coagu laçāo realizados durante a internaçào no CTI encontra-se no Quadro 2.

QUADRO2

Resultados dos testes de coagulaçáo realizados no paciente do caso n: 2 após picada por Crotalus durissus terrificus

\begin{tabular}{lcccc}
\hline & & \multicolumn{3}{c}{ horas após a picada } \\
Teste & valor normal & 24 & 36 & 60 \\
\hline TC (min) & 15 & infinito & -- & - \\
TP $(s)$ & 13 & 52 & 19 & 13 \\
TTP (s) & 35 & 180 & 39 & 51 \\
Fibrinogenio $\left(\mathrm{mg}^{\prime} /\right)$ & $150-350$ & zero & 86 & 220 \\
Plaquetas $\left(X 10^{3} \mathrm{~mm}^{3}\right)$ & $150-350$ & 242 & 460 & 365 \\
\hline
\end{tabular}

$\mathrm{TC}=$ tempo de coagulaça $: \mathrm{TP}=$ tempo de protrombina: $\mathrm{TTP}$ $=$ tempo de tromboplastina parcial

\section{DISCUSSĀO}

O veneno da cascavel sul-americana possui atividade coagulante 9.10,15.17 $^{\text {capaz de ocasionar }}$ incoagulabilidade sangüinea em $40 \%$ dos pacientes picados por esta serpente ${ }^{13}$. A atividade coagulante é do tipo trombina, convertendo o fibrinogênio diretamente em fibrina ${ }^{12}$ mas dela difere pois a fibrina formada tende a ser instável, predominando o efeito hipofibrinogenante sem que ocorram manifestações de coagulação intravascular disseminada. A atividade coagulante também é descrita no veneno de outras espécies do gênero Crotalus ${ }^{5.12}$ como a Crotalus adamanteus (cascavel norte-americana) no qual não se observa efeito ativador dos fatores II, VII e X e tampouco agregação plaquetária.

Nos casos relatados, observou-se afibrinogenemia associada ao prolongamento do TC, TTP e TP sem haver reduçāo do número de plaquetas. Estas alterações não são compatíveis com o diagnóstico de coagulaçāo intravascular disseminada devido a não ter havido consumo de plaquetas, podendo ser explicadas pela atividade 
AMARAL. C. F. S.; REZENDE, N. A.; PEDROSA, T. M. G.: SILVA. O. A da \& PEDROSO, E. R, P - Afibrinogrnemia secundaria a acidente ofídico crotálico (Crotalus durissus terrificus). Rev. Inst. Med. trop. Sâ Paulo, 30 (4): 288-292. 1988

tipo trombina do veneno crotálico. O caso n: 1 , previamente relatado', recebeu quantidade nào conhecida e não especificada de antiveneno. Trinta e duas horas depois da picada apresen. tava afibrinogenemia, prolongamento do TC, TTP e do TP com número normal de plaquetas. Foi feito o diagnóstico de fibrinólise primária, tendo o paciente sido tratado com ácido épsilon. aminocapróico e transfusāo de sangue fresco total. Embora não se possa afastar a possibilidade de que o veneno crotálico ative o plasminogênio produzindo fibrinólise. a normalizaçáo dos testes de coagulaçāo neste paciente por ter se processado independentemente das medidas tera pêuticas empregadas. Por outro lado, o uso de antifibrinolíticos não está isento de risco pois pode provocar estabilizaçào da fibrina que se forma em excesso pela açāo coagulante do veneno crotálico, com possibilidade de instalação de quadro de coagulação intravascular disseminada, o que, felizmente, nào foi observado. Por este motivo, julga-se que o emprego de antifibrinolíticos só se justifica se houver comprovaçāo laboratorial de fibrinólise primária.

No caso n? 2 observou-se normalizaçāo do TTP e aparecimento de fibrinogenio doze horas após o emprego do antiveneno específico em dose adequada.

Nos dois casos relatados, apesar das alteraçōes acentuadas dos testes de coagulaçảo, as manifestações hemorrágicas foram ausentes ou discretas. Estas observaçoes sugerem que o emprego do antiveneno específico em doses ade quadas seja suficiente para o tratamento dos distúrbios de coagulaçāo observados nos acidentes crotálicos. Apesar da utilizaçâo de sangue fresco total no caso n: 1, julga-se que a conduta mais apropriada seja expectante, e, se surgirem manifestaçōes hemorrágicas importantes, o tratamento adequado seja a reposiçāo do fibrinogènio com crioprecipitado enquan to se aguarda a neutralização do veneno pelo antiveneno específico.

A intensidade das alteraçōes dos testes de coagulação pode constituir parâmetro de gravidade nos acidentes crotálicos. É possivel tam bém que, à semelhança do que ocorre no envene namento botrópico, as determinaçōes seriadas destes testes possam orientar a administraçāo de doses adicionais de antiveneno. Entretanto. estudos prospectivos envolvendo maior numero de pacientes sào necessários nāo só para testar estas hipoteses como também para melhor conhecimento da evolução destes distúrbios.

Além dos distúrbios de coagulacáo os dois pacientes apresentaram insuficiência renal agn da não oligúrica tratada conservadoramente $O$ caso n: 2 apresentou elevaçāo sérica dos niveis de CPK. TGO e LDH compativeis com o diag nóstico de rabdomiólise secundária a atividade miotóxica do veneno ${ }^{2.14}$.

\section{SUMMARY}

\section{Afibrinogenemia following snake bite (Crotalus durissus terrificus)}

This paper reports two cases of afibrinogenemia with normal platelet count following Crotalus durissus terrificus, snake bite. Both pa tients presented high output acute renal failure and case two also had increased blood levels of $\mathrm{CPK}$ and $\mathrm{LDH}$ compatible with the diagnosis of rhabdomyolysis. Case one was given an unk nown amount of antivenom and was treated with epsilonaminocaproic acid and a fresh whole blood transfusion and showed recovery of the coagulation disturbance 40 hours following these measures. Case two was given an adequate amount of crotalide antivenom and the coagulation tests performed 12 hours later showed a normal partial thromboplastin time and fibrino gen $86 \mathrm{mg} / 100 \mathrm{ml}$. Case one presented no haemorrhagic disturbances. Case two presented persistent bleeding following venopuncture and after removal of impetigo crust in the legs. Acute renal failure was treated conservatively and both pa tients were discharged from the hospital with recovery of the renal function.

\section{REFERENCIAS BIBLIOGRAFICAS}

1. AMARAL. C. F. S.: SILVA. O. A. da: LOPEZ. M. \& PE DROSO. E. R. P. ... Afibrinogenemia following snake bite (Crotalus durissus terrificus). Amer. J. trop. Med. Hyg. 29: 1453 1455. 1980

2. AZEVEDO MARQUES. M. M.: CUPO. P : COIMBRA, T M.: HERING, S E : ROSSI, M A \& LAURE. G J - My" necrosis. myoglobinuria and acute renal failure induced by south-America rattlesnake iCrotalus durissus terrificus) envenomation in Brazil. Toxicon, 23:631636. 1985 
AMARAL. C. F. S.: REZENDE. N. A.: PEdrosa, T. M. G.; SIlva. O. A da \& PEDROSO, E. R. P. - Afibrinogenemia secundária a acidente ofídico crotálico (Crotalus durissus terrificus). Rev. Inst. Med. trop. Sào Paulo, 30 (4): 288292,1988

3. AZEVEDO.MARQUES. M. M. HERING. S. E. \& CUPO. P. - Avaliaçāo da hemolise em envenenamento crotálico humano. Rev. Soc. bras. Med. trop., 20 isupl: 55, 1987

4. AZEVEDO MARQUES, M. M.: HERING. S. E. \& CUPO P. - Evidence that Crotalus durissus terrificus tsouth $A$ merica rattlesnakr envenomation in human causes myo lisis rather hemolysis. Toxicon, 25: 1663, 1668, 1987.

5. BISMUTH, C.: CHOUVALIDZE, N.: BAND, F.: SORIA C.: DROUET, L. \& TOBELEM, G. - Défibrination pure apres morsure de crotale horridus. Presse med., 12: 9193 1983

6. BRAZIL. V. - Serum therapie anti ophidism. Rev. med. S. Paulo, 12: 293. 1909

7. BRAZIL, V. - La défence contre l'ophidisme. $3 \mathrm{ed}$ Săo Paulo, Pocai Weiss \& C., 1914

8. BRAZIL, V. \& RANGEL PESTANA, B. - Nova contri buiçāo ao estudo do envenenamento ophidico. V. Açäo physiologica. Rev. med. S. Paulo, 12: 415, 1909

9. BRAZIL, V. \& RANGEL PESTANA, B. - Nova contri buiçào ao estudo do envenenamento ophidico. VI. Açao coagulante. Rev. med. S. Paulo, 12: 439.1909

10. BRAZIL, V \& VELLARD, J.--Action coagulante et anti coagulante des venims. Ann. Inst. Pasteur, 42: 403451 1928

11. BUDZYNSKI, A.: PANDYA, B. U.; RUBIN, R. N : BRI ZUELA. B. S.: SOSZKA. T. \& STEWART, G. J. - Fibrino genolytic afibrinogenemia after envenomation by wes terndiamondback rattlesnake (Crotalus atrox). Blood, 63 : $1 \cdot 14,1984$
12. DENSON K. W. E: RUSSEL, F. E. ALMAGRO D \& BISHOP, R. C. - Caracterization of coagulant activity of some snake venoms. Toxicon, 10:557562.1972.

13. JORGE, M, T. \& RIBEIRO, L. A. - Incoagulabilidade sanguinea no aridente rotalico. In: CONGRESSO DA SOCIEDADE BRASILEIRA DE MEDICINA TROPICAL, 24. Manaus. 1988. Programa e resumos. Manaus, Ed Um berto Calderaro. 1988. p. 121. res. n. 243. Revista da Socio dade Brasileira de Modieina Tropical, 21 ISupl 1. 1988

14. MAGALHAES. R. A.: RIBEIRO $M$ M $\mathrm{F}^{2}$ REZENDE. N. A. \& AMARAL. C. F. S. - Rabdomiolise secundaria a acidente afidico erotálico (Crotalus durissus terrificus). Rev. Inst. Med. trop. S. Paulo, 28: 228233,1986

15. ROSENFELD, G.: HAMPE, O. G. \& KELEN, E. M. A - Coagulant and fibrinolytic activity of animal venoms: determination of coaguiant and fibrinolytic index of ciffe rent species. Mem. Inst. Butantan, 29: 143163, 1959.

16. ROSENFELD, G; KELLEN, E. M. A. \& NUDEL, F.Hemolytic activity of animal venoms. I.Classification in different types and activities. Mem. Inst. Butantan, 30: 117132,1960

17. ROSENFELD. G. -.. Acidentes por animais peçonhentos (serpentes, aranhas e escorpioes). In: VERONESI. R. -Doencas infecciosas e parasitarias. 6: ed. Rio de Janeiro, Guanabara Koogan. 1976. p. 970983.

18. WEISS, H J : ALLAN, S.: DAVIDSON E. \& KOCHWA S. - Afibrinogenemia in man following the bite of a rattles. nake Crotalus adamanteus). Amer. J. Med., 47: 625634 , 1969

Recibo para public açào em 14:8 1987 